\title{
Pengaruh pola asuh orangtua terhadap tingkat kecemasan anak sebelum menjalani perawatan penambalan gigi Di RSGM Unsrat
}

\author{
${ }^{1}$ Patricia S. Sagrang \\ ${ }^{2}$ Vonny N. S. Wowor \\ ${ }^{2}$ Christy N. Mintjelungan \\ ${ }^{1}$ Kandidat Skripsi Program Studi Pendidikan Dokter Gigi Fakultas Kedokteran \\ ${ }^{2}$ Program Studi Pendidikan Dokter Gigi Fakultas Kedokteran \\ Universitas Sam Ratulangi Manado \\ Email: patriciashery109@gmail.com
}

\begin{abstract}
One problem of a child behavior that often occurs when they undergo dental treatment is anxiety. There are many factors that can cause anxiety in children, inter alia the style of parenting applied to their children. There are three kinds of parenting, as follows: authoritarian, authoritative, and permissive. This study was aimed to analyze the influence the parenting style upon the child anxiety before dental filling treatment at RSGM Unsrat (dental clinic). This was a descriptive analytical study with a cross sectional design. There were 31 respondents obtained by using purposive sampling method. Data were collected from parenting questionnaires and CFSS-DS (Children Dental Fear Survey Schedulesubscale) and were analyzed by using the Fisher test. The results showed the percentages of parenting, as follows: authoritative parenting $46.87 \%$, authoritarian parenting $34.37 \%$, and permissive parenting $18.76 \%$. Child anxiety levels before dental filling treatment were lowlevel anxiety $65.62 \%$ and moderate-level anxiety $34.38 \%$; high-level anxiety was not found. The Fischer test analyzing the effect of parenting style on anxiety showed a p-value of 0.01 . Conclusion: There was a significant effect of parenting style on the child anxiety level before dental filling treatment at RSGM Unsrat.
\end{abstract}

Keywords: parenting styles, anxiety

\begin{abstract}
Abstrak: Salah satu sumber masalah pada perilaku yang sering terjadi saat anak menjalani perawatan gigi dan mulut yakni kecemasan. Terdapat banyak faktor yang dapat memengaruhi rasa cemas pada anak, salah satunya ialah gaya pola asuh yang diterapkan orang tua kepada anaknya. Pola asuh terdiri dari 3 macam, yaitu otoriter, demokratis, dan permisif. Penelitian ini bertujuan untuk menganalisis pengaruh pola asuh orang tua terhadap tingkat kecemasan pasien anak sebelum menjalani perawatan penambalan gigi di RSGM Unsrat. Jenis penelitian ialah deskriptif analitik dengan desain potong lintang. Jumlah sampel sebanyak 32 responden diperoleh dengan purposive sampling. Data dikumpulkan melalui kuesioner pola asuh orangtua dan kuesioner CFSS-DS (Children Fear Survey ScheduleDental Subscale) dan dianalisis menggunakan uji Fisher. Hasil penelitian mendapatkan pola asuh demokratis sebesar $46,87 \%$, pola asuh otoriter $34,37 \%$, dan pola asuh permisif $18,76 \%$. Tingkat kecemasan anak sebelum menjalani perawatan penambalan gigi di RSGM Unsrat ialah: tingkat kecemasan rendah $65,62 \%$, tingkat kecemasan sedang $34,38 \%$ tidak dijumpai tingkat kecemasan tinggi tidak ada. Analisis data dengan uji Fisher mendapatkan nilai $\mathrm{p}=0,01$. Simpulan: Terdapat pengaruh pola asuh orangtua terhadap tingkat kecemasan anak sebelum menjalani perawatan penambalan gigi di RSGM Unsrat.
\end{abstract}

Kata kunci:pola asuh, tingkat kecemasan 
Perawatan dalam bidang kedokteran gigi berbeda dengan perawatan dalam bidang kedokteran. Bagi sebagian masyarakat termasuk anak-anak, perawatan di bidang kedokteran gigi menimbulkan kesan yang 'menakutkan', sehingga agak menyulitkan terutama bagi pasien-yang baru pertama kali menjalani perawatan. Salah satu sumber masalah pada perilaku yang sering terjadi saat anak menjalani perawatan gigi dan mulut yakni kecemasan.

Kecemasan merupakan suatu keadaan emosi individu yang normal untuk mempertahankan diri pada situasi tertentu yang dirasakan sebagai suatu ancaman. ${ }^{2}$ Prevalensi kecemasan dental yang terjadi di beberapa negara berkisar 5-20\% dengan populasi paling banyak terlihat pada anakanak. $^{2}$ Menurut hasil penelitian yang dilakukan oleh Blomqvist et al. ${ }^{3}$ didapatkan bahwa kecemasan dental yang terjadi pada anak relatif umum yaitu berkisar $5,7 \%$ sampai $6,7 \%$. Penelitian Manurung ${ }^{4}$ menunjukkan bahwa 26,7 \% anak memiliki rasa sangat cemas terhadap perawatan gigi dan mulut. ${ }^{4}$

Dalam praktek dokter gigi sering dijumpai anak merasa cemas terhadap tindakan penambalan gigi, bahkan sebelum dilakukan perawatan penambalan gigi. Rasa cemas akan muncul dalam benak anak karena imajinasi anak itu sendiri, misalnya mendengar suara mesin bur akan membangkitkan persepsi terhadap rasa nyeri. Menurut hasil penelitian yang dilakukan Wuisan ${ }^{5}$ terdapat $46 \%$ pasien anak mengalami cemas berat sebelum melakukan perawatan penambalan gigi.

Terdapat banyak faktor yang dapat menimbulkan rasa cemas pada anak, salah satunya ialah lingkungan keluarga. Orangtua merupakan contoh dan teladan bagi anak. Anak akan meniru setiap perilaku orangtuanya. Gaya pola asuh yang diterapkan orang tua kepada anak memiliki kaitan dalam mengembangkan kemampuan anak untuk bersosialisasi terhadap lingkungan sekitar. ${ }^{6}$ Baumrind membagi pola asuh atas: pola asuh otoriter, demokratis, dan permisif. ${ }^{7}$

Menurut teori Bowlby dalam at $a$ glance kedokteran gigi menyatakan bahwa perkembangan anak paling mudah dipahami dalam bentuk pola interaksi antara anak dengan pengasuh utama dalam kehidupan sehari-hari. Bila terdapat masalah dalam hubungan ini, maka anak cenderung membentuk pola kecemasan yang dapat memengaruhi hubungan yang optimal dengan orang lain. ${ }^{8}$

Penelitian ini bertujuan untuk mengetahui gambaran pola asuh orangtua dan tingkat kecemasan anak sebelum menjalani perawatan penambalan gigi, serta mengetahui pengaruh pola asuh orangtua terhadap tingkat kecemasan anak sebelum menjalani perawatan penambalan gigi.

\section{METODE PENELITIAN}

Jenis penelitian ini ialah deskriptif analitik dengan dessain potong lintang. Penelitian ini dilakukan di RSGM Unsrat pada bulan Februari-Agustus 2016. Populasi pada penelitian ini yaitu pasien anak usia 8-12 tahun yang melakukan perawatan penambalan gigi dan orangtua yang mendampingi pasien anak. Metode sampel yang digunakan ialah purposive sampling. Instrumen penelitian yang digunakan yaitu kuesioner pola asuh dan kuesioner CFSS-DS (Children Fear Survey Schedule-Dental Subscale). Analisis data dalam penelitian ini menggunakan uji Fisher.

\section{HASIL PENELITIAN}

Karakteristik sampel berdasarkan jenis kelamin dan usia dapat dilihat pada Tabel 1 dan 2.

Tabel 1. Karakteristik responden berdasarkan jenis kelamin

\begin{tabular}{ccc}
\hline & Frekuensi \\
Jenis kelamin & $(\mathbf{n})$ & $\boldsymbol{\%}$ \\
\hline Perempuan & 16 & 50,00 \\
Laki-laki & 16 & 50,00 \\
Total & 32 & 100 \\
\hline
\end{tabular}

Tabel 3 menunjukkan bahwa pola asuh yang paling banyak ditemukan dan diterapkan oleh responden yaitu pola asuh demokratis sebanyak 15 orang $(46,67 \%)$, 
diikuti dengan pola asuh otoriter sebanyak 11 orang $(34,37 \%)$, dan pola asuh yang paling sedikit ditemukan dan diterapkan oleh responden yaitu pola asuh permisif sebanyak 6 orang $(18,75 \%)$.

Tabel 4 menunjukkan bahwa tingkat kecemasan responden anak sebelum menjalani perawatan penambalan gigi paling banyak yakni kecemasan tingkat rendah sebanyak 21 anak $(62,50 \%)$, disusul dengan kecemasan tingkat sedang sebanyak 11 anak (34,37\%), sedangkan kecemasan tingkat tinggi tidak ada.

Tabel 2. Karakteristik responden anak berdasarkan usia

\begin{tabular}{ccc}
\hline Usia (tahun) & Frekuensi (n) & \% \\
\hline $8-10$ & 31 & 96,88 \\
$11-12$ & 1 & 3,12 \\
Total & 32 & 100
\end{tabular}

\begin{tabular}{ccccccccc}
\hline & \multicolumn{8}{c}{ Tingkat Kecemasan } \\
\cline { 2 - 9 } Usia (tahun & \multicolumn{2}{c}{ Rendah } & \multicolumn{2}{c}{ Sedang } & \multicolumn{2}{c}{ Tinggi } & \multicolumn{2}{c}{ Total } \\
\cline { 2 - 9 } & $\mathrm{N}$ & $\%$ & $\mathrm{~N}$ & $\%$ & $\mathrm{~N}$ & $\%$ & $\mathrm{~N}$ & $\%$ \\
\hline $8-10$ & 20 & 95,24 & 11 & 100 & 0 & 0 & 31 & 96,88 \\
$11-12$ & 1 & 4,76 & 0 & 0 & 0 & 0 & 1 & 3,12 \\
Total & 21 & & 11 & & 0 & & 32 & 100 \\
\hline
\end{tabular}

Tabel 3. Distribusi hasil penilaian pola asuh orangtua

\begin{tabular}{ccc}
\hline $\begin{array}{c}\text { Pola asuh } \\
\text { orang tua }\end{array}$ & $\begin{array}{c}\text { Frekuensi } \\
(\mathbf{n})\end{array}$ & $\%$ \\
\hline Demokratis & 15 & 46,87 \\
Otoriter & 11 & 34,37 \\
Permisif & 6 & 18,76 \\
Total & 32 & 100 \\
\hline
\end{tabular}

Tabel 4. Distribusi tingkat kecemasan responden anak

\begin{tabular}{ccc}
\hline $\begin{array}{c}\text { Tingkat } \\
\text { kecemasan }\end{array}$ & $\begin{array}{c}\text { Frekuensi } \\
(\mathrm{n})\end{array}$ & $\%$ \\
\hline Rendah & 21 & 65,62 \\
Sedang & 11 & 34,38 \\
Tinggi & 0 & 0 \\
Total & 32 & 100 \\
\hline
\end{tabular}

Tabel 5 menunjukkan bahwa tingkat kecemasan sedang didominasi oleh anak usia 8-10 tahun yaitu sebanyak 11 anak $(34,38 \%)$ sedangkan kecemasan tingkat rendah didominasi anak usia 8-10 tahun yaitu sebanyak 20 anak $(95,24 \%)$.

Tabel 6 menunjukkan bahwa tingkat kecemasan rendah paling banyak ditemukan pada pola asuh demokratis sebanyak 13 orang $(86,7 \%)$. Kategori tingkat kecemasan sedang paling banyak ditemukan pada pola asuh permisif sebanyak 5 orang $(83,3 \%)$. Berdasarkan analisis data dengan uji Fischer diperoleh nilai $\mathrm{p}=0,01 \quad(<0,05)$ yang menunjukkan bahwa terdapat pengaruh pola asuh orangtua terhadap tingkat kecemasan anak. 
Tabel 5. Distribusi tingkat kecemasan berdasarkan usia

\begin{tabular}{ccccccccc}
\hline \multirow{2}{*}{$\begin{array}{c}\text { Usia } \\
\text { tahun) }\end{array}$} & \multicolumn{7}{c}{ Tingkat Kecemasan } \\
\cline { 2 - 8 } & Rendah & \multicolumn{2}{c}{ Sedang } & \multicolumn{2}{c}{ Tinggi } & \multicolumn{2}{c}{ Total } \\
\cline { 2 - 9 } & $\mathrm{N}$ & $\%$ & $\mathrm{n}$ & $\%$ & $\mathrm{n}$ & $\%$ & $\mathrm{n}$ & $\%$ \\
\hline $8-10$ & 20 & 95,24 & 11 & 100 & 0 & 0 & 31 & 96,88 \\
$11-12$ & 1 & 4,76 & 0 & 0 & 0 & 0 & 1 & 3,12 \\
Total & 21 & & 11 & & 0 & & 32 & 100 \\
\hline
\end{tabular}

Tabel 6. Pengaruh pola asuh orangtua terhadap tingkat kecemasan anak

\begin{tabular}{ccccccccccc}
\hline \multirow{2}{*}{ Pola asuh orangtua } & \multicolumn{8}{c}{ Tingkat kecemasan } \\
\cline { 2 - 12 } & \multicolumn{2}{c}{ Rendah } & \multicolumn{1}{c}{ Sedang } & \multicolumn{2}{c}{ Tinggi } & \multicolumn{3}{c}{ Total } & \\
\cline { 2 - 11 } & $\mathrm{N}$ & $\%$ & $\mathrm{~N}$ & $\%$ & $\mathrm{n}$ & $\%$ & $\mathrm{n}$ & $\%$ & $P$ \\
\hline Demokratis & 13 & 86,7 & 2 & 13,3 & 0 & 0 & 15 & 100 & \\
Otoriter & 7 & 63,6 & 4 & 36,4 & 0 & 0 & 11 & 100 & 0,01 \\
Permisif & 1 & 16,7 & 5 & 83,3 & 0 & 0 & 6 & 100 & \\
\hline
\end{tabular}

\section{BAHASAN}

Hasil penelitian mendapatkan tingkat kecemasan rendah paling banyak ditemukan pada anak laki-laki, yaitu sebanyak 12 anak (75\%). Hal ini dapat terjadi karena anak perempuan lebih peka secara emosi dan lebih terbuka dalam mengekspresikan apa yang ada pada perasaannya dibandingkan dengan laki-laki yang cenderung lebih tenang dan memendam rasa emosi yang dirasakan. Hasil ini didukung oleh penelitian yang dilakukan Raj et.al. ${ }^{9}$

Berdasarkan karakterisitik jenis kelamin (Tabel 5), diperoleh tingkat kecemasan sedang paling banyak ditemukan pada responden yang berusia 8-10 tahun $(95,24 \%)$. Hal ini terjadi oleh karena jumlah responden yang berusia 810tahun lebih dominan, sehingga hasil penelitian menunjukkan kecemasan sedang paling banyak dialami pada kelompok usia ini. Kondisi seperti ini juga dapat disebabkan oleh karena semakin besar usia anak, maka daya tangkap dalam memahami suatu informasi lebih cepat dan sudah mampu berpikir secara logik. Hasil ini sejalan dengan penelitian yang dilakukan oleh Sanda et al. ${ }^{10}$ di Romania. ${ }^{10}$

Hasil penelitian yang didapatkan (Tabel 4) menunjukkan lebih banyak responden yang mengalami kecemasan rendah $(65,62 \%)$. Terdapat beberapa faktor lain yang dapat memengaruhi kecemasan anak di antaranya, yaitu peranan dokter gigi. Hal ini sejalan dengan penelitian yang dilakukan oleh Bernstein et al. ${ }^{11}$ yang menyatakan bahwa kelompok rasa takut rendah kebanyakan ditemukan oleh karena peranan dokter gigi yang berhati-hati,sabar, dan ramah.

Pengalaman dental pribadi merupakan salah satu faktor yang dapat memengaruhi kecemasan. Nigam ${ }^{2}$ mengemukakan bahwa anak yang merasa cemas pernah menjalani perawatan dental yang buruk sebelumnya yang dapat memengaruhi kualitas emosi anak. Sebaliknya, bila pengalaman dental yang dialami anak itu baik maka anak tidak akan merasa cemas dan dapat kooperatif menjalani suatu perawatan.

Faktor lain yang dapat memengaruhi yaitu pengalaman dental dari orang lain. Shaw menemukan bahwa anak yang cemas dikarenakan anggota keluarga atau kerabat yang cemas akibat dari pengalaman dental yang buruk sebelumnya. Hal tersebut dijadikan sebagai contoh pada anak-anak konsekuensi yang diperoleh dari kunjungan ke dokter gigi, serta mengubah cara berpikir anak terhadap perawatan gigi dan mulut. $^{11}$ 
Pandangan dari orangtua tentang dokter gigi merupakan faktor lainnya yang dapat memengaruhi kecemasan anak. Menurut Ramadhan ${ }^{12}$ hal ini dapat terjadi oleh karena banyak orangtua memberikan pandangan yang salah dan menakutkan tentang dokter gigi kepada anak. Apabila anak tidak patuh, maka dibawa ke dokter gigi merupakan salah satu bentuk ancaman agar anak bisa patuh kepada orangtua. ${ }^{12}$

Kondisi lingkungan praktek juga dapat memengaruhi kecemasan anak karena lingkungan dan situasi perawatan gigi itu sendiri sudah memicu kecemasan. Hal tersebut dapat terjadi karena pasien dihadapkan dengan stimuli sensori yang dapat menimbulkan rasa tidak nyaman. ${ }^{13}$

Faktor lain yang memengaruhi ialah pola asuh orangtua. Sebagai pengasuh utama, orangtua jauh lebih memahami perilaku dan kondisi anak, namun orangtua sering tidak menyadari bahwa pola asuh dapat memengaruhi perilaku dan perkembangan psikologis anak, antara lain masalah perilaku anak dalam menjalani perawatan gigi dan mulut berupa kecemasan. ${ }^{14}$

Tabel 6 menunjukkan bahwa anak yang diasuh dengan pola asuh demokratis, banyak mengalami kecemasan tingkat rendah $(86,7 \%)$. Hasil ini sejalan dengan penelitian Howenstein ${ }^{15}$ yang menunjukkan bahwa pola asuh demokratis memiliki pengaruh yang lebih positif terhadap perilaku anak. Orangtua yang menerapkan pola asuh demokratis bertindak sebagai contoh dan teladan yang baik terhadap anak mereka, sehingga anak meniru dan mempelajari perilaku yang positif dari orangtua mereka. Hasil penelitian pada

Tabel 6 juga memperlihatkan orangtua yang otoriter memiliki anak dengan tingkat kecemasan sedang $(36,4 \%)$. Hal ini menunjukkan hasil yang lebih tinggi bila dibandingkan dengan pola asuh demokratis. Penelitian sebelumnya yang dilakukan oleh Taganing ${ }^{16}$ menunjukkan bahwa pola asuh orangtua yang otoriter dapat menyebabkan anak menjadi sulit bersosialisasi, penakut dan memiliki kemampuan komunikasi yang kurang. ${ }^{16}$
Anak dengan pola asuh permisif merupakan responden yang paling banyak mengalami kecemasan tingkat sedang $(83,3 \%)$ (Tabel 6). Hasil penelitian ini didukung oleh penelitian Bibi et al. ${ }^{6}$ yang menyatakan bahwa orangtua permisif dapat menimbulkan tingkat kecemasan anak yang lebih tinggi dan masalah internal seperti masalah sosial dan depresi.

Hasil uji Fisher mendapatkan nilai $\mathrm{p}=0,01 \quad(<0,05)$ yang berarti terdapat pengaruh pola asuh orangtua terhadap tingkat kecemasan anak.

\section{SIMPULAN}

Dari hasil penelitian ini dapat disimpulkan bahwa pola asuh orangtua yang terbanyak ialah pola asuh demokratis, selanjutnya pola asuh otoriter, dan pola asuh permisif.

Tingkat kecemasan anak sebelum menjalani perawatan penambalan gigi di RSGM Unsrat umumnya rendah. Juga dijumpai anak dengan tingkat kecemasan sedang namun tidak dijumpai anak dengan tingkat kecemasan tinggi.

Terdapat pengaruh bermakna dari pola asuh orangtua terhadap tingkat kecemasan anak sebelum menjalani perawatan penambalan gigi di RSGM Unsrat.

\section{SARAN}

1. Diharapkan kepada orangtua agar dapat menerapkan pola asuh demokratis agar dapat memberikan dampak yang positif terhadap perkembangan perilaku anak sehari-hari.

2. Diharapkan untuk penelitian selanjutnya dapat dilakukan dengan jumlah sampel yang lebih besar dan di lingkungan yang berbeda, serta melakukan uji analisis masing-masing kategori pola asuh orangtua.

\section{DAFTAR PUSTAKA}

1. Setiawan AS. Aplikasi teori belajar sosial dalam penatalaksanaan rasa takut dan cemasan anak pada perawatan gigi. Majalah Kedokteran Gigi Bandung. 2014, p.87-91.

2. Nigam AG, Marwah N, Goenka $P$, 
Chaudry A. Correlation of general anxiety and dental anxiety in children aged 3 to 5 years: A clinical survey. $\mathrm{J}$ Int Oral Health. 2013, p.18-24.

3. Blomqvist $\mathbf{M}$, et al.Cognitive ability and dental fear and anxiety. European Journal of Oral Science 2013, p.117120.

4. Manurung NK. Gambaran tingkat kecemasan anak terhadap pelayanan kesehatan gigi dan mulut pada siswa kelas V-B SD St. Antonius Jl. Sriwijaya no.7 Medan. Jurnal Ilmiah Panmed. Medan : Poltekkes Menkes. 2014, p. 157-161

5. Wuisan M. Gambaran kecemasan terhadap penambalam gigi pada anak umur 6-12 tahun di poli gigi dan mulut puskesmas Tuminting Manado. eG. 2015, p.203208.

6. Lara A. Crego A, Maroto M R. Emotional of dental fear to children: the father's mediating role in parental transfer of fear. Int J Pediatric Dent. 2012;22:3245.

7. Bibi F, Caudhry A G, Awan E A, Tariq B. Contribution of parenting style in domain of children. IOSR Journal of Humanities and Social Science. 2013; p.91-95.

8. Duggal M, Cameron A, Toumba J. At a glance Kedokteran Gigi Anak. Jakarta: Erlangga, 2014; p.11-3.

9. Raj S, et al.Evaluation of dental fear during first dental visit using children's fear survey schedule-dental subscale. International Journal of Clinical
Pediatric Dentistry. India: AECS Maruti Dental College Bengaluru. 2013, p.12-15. Available at URL: www.jaypeejournals.com/.../ShowText. aspx.

10. Sanda P, et al. Dental anxiety and its association with behavioural factors in children. Current Health Science Journal. Romania: Editura Medicala Universitara.2014. Available from: URL: https: // www. ncbi. nlm. nih. gov / pmc /articles/PMC4709712/.

11. Blinkorn AS, Kent GG. Pengelolaan tingkah laku pasien pada praktik dokter gigi (2nd ed). Jakarta: EGC, 2005; p.63-86.

12. Ramadhan AG. Serba serbi kesehatan gigi dan mulut. Jakarta: Bukune, 2010.

13. Sulastri R. Rasa takut pasien anak usia 611 tahun terhadap perawatan gigi di klinik pedodonsia RSGMP FKG USU Medan. Medan: Universitas Sumatera Utara; 2014.

14. Suprabha, Rao A, Choudhary S, Shenoy R. Child dental fear and behavior, the role of environmental factors in hospital cohort. Journal of Indian Society of Pedodontic and Preventive Dentistry. 2011;29 (2):95-6.

15. Howenstein J. Correlating parenting styles with the child's caries and behavior in dental office [Thesis]. Ohio: The Ohio State University; 2014.

16. Taganing NM, Fortuna F. Hubungan pola asuh otoriter dengan perilaku agresif pada remaja. Jakarta: Universitas Gunadarma; 2008. 